\title{
A ESCALA NAS CIÊNCIAS ATMOSFÉRICAS
}

\section{Lucí Hidalgo NUNES}

\section{INTRODUÇÃO}

A escala de abordagem é um dos aspectos mais importantes das ciências atmosféricas, definindo numa pesquisa não apenas a área e período de abrangência, mas também as técnicas e os métodos a serem empregados em busca de seus objetivos.

Mesmo sendo ponto central em estudos atmosféricos, essa discussão tem merecido pouco destaque na literatura. Além disso, existe confusão de várias ordens, como terminologia, extensão horizontal/vertical de abrangência dos níveis escalares, processos dominantes em cada um, etc. Apesar de essa questão nunca se encerrar, devendo ser sempre revista de acordo com os progressos das ciências atmosféricas, o que se verifica no momento é uma grande falta de consenso, o que suscita dúvidas diversas quanto a esta temática fundamental.

A fim de apresentar as divergências encontradas na literatura, é analisada, a seguir, a contribuição distinta de autores quanto ao tratamento escalar, de modo a assinalar as diferenças entre elas e estimular a discussão.

\section{A QUESTÃO, SEGUNDO DIFERENTES AUTORES}

RIBEIRO (1992) destaca que a integração de fenômenos num dado tempo e espaço criaria unidades, sendo que a cada nível escalar correponderia uma abordagem específica, coerente com a extensão espacial, duração do fenômeno e técnicas analíticas empregadas.

A taxonomia proposta pela autor baseia-se em alguns critérios: 1. distinção entre escalas superiores (mais próximas do nível planetário) e inferiores (mais próximas da superfície terrestre); 2. os processos físicos interativos em escalas superiores modificariam sucessivamente $o$ comportamento da atmosfera em escalas inferio- res; 3 . os processos físicos em escalas inferiores repercutiriam de forma limitada nos processos superiores; 4. quanto mais extenso o resultado de determinada combinação, maior o tempo de sua permanência e vice-versa e 5 . a extensão de determinada combinação na atmosfera resultaria em atributo tridimensional.

Como base para a taxonomia, apresenta três níveis interativos: 1 macroclimático: interação entre radiação solar, curvatura da terra e movimentos de rotação e translação; 2. mesoclimático: interação entre energia disponível para processos de evaporação e geração de campos de pressão e feições do meio terrestre; e 3. microclimático: interação entre sistemas ambientais particulares na modificação dos fluxos de energia, umidade, massa e momentum.

As ordens de grandeza propostas são: 1 . clima zonal: onde se define a circulação geral da atmosfera, com extensão horizontal de 1.000 a $5.000 \mathrm{~km}$, e vertical, abrangendo toda a atmosfera, com duração de um estado climático de uma semana a seis meses; 2 . clima regional: gerado pela ação modificadora da circulação geral da atmosfera provocada por fatores de superfície que engendram os centros de ação. Sua extensão horizontal situa-se entre 150 e $2.500 \mathrm{Km}$, limitando-se a vertical à abaixo da tropopausa. Os estados de tempo durariam de 1 a 30 dias; 3 . clima local ou mesoclima: gerados pelas variações no interior do clima regional graças a feições fisiográficas - com destaque para o relevo - ou antrópicas - como alteração da cobertura do solo e composição da atmosfera. A escala espacial de abrangência varia de 1,5 a $800 \mathrm{~km}$, embora geralmente se considere a amplitude de variação média entre 15 e $150 \mathrm{~km}$.; as variações estariam compreendidas entre 12 horas e uma semana; 4. topoclima: derivação do clima local dada a rugosidade do terreno. Sua extensão horizontal se estende de 0,5 a $5 \mathrm{~km}$, e a vertical, de 50 a $100 \mathrm{~m}$. A duração dos processos seria bastante efêmera e 5. microclima: definido pela amplitude das trocas gasosas e energéticas entre 
feições ou estruturas particularizadas dispostas na superfície terrestre e o ar que as envolve. Seus limites são de difícil definição, variando de 0,1 a $10.000 \mathrm{~m}$.

ORLANSKI (1975) coloca que a dinâmica atmosférica é classicamente estudada de maneiras que se diferenciam bastante quanto à escala espaço-temporal: 1. macroclima: cujos estudos teriam por meta predizer a evolução do padrão de tempo (dinâmica de grande escala), abrangendo milhares de $\mathrm{km}$ e tempo de uma semana; 2. mesoclima: intermediário, envolvendo grande números de observações e processos abrangendo de 10 a $1.000 \mathrm{~km}$ e muitos dias e 3 . microclima: que procuraria explicar o comportamento do ambiente imediato em que vive o homem, abrangendo processos da ordem de vários metros e minutos. O autor apresenta uma taxonomia, salientado a diferença dinâmica entre processos que possam estar no mesmo nível taxonômico e os processos físicos relacionados. Ressalta que, por motivos práticos, a escala do movimento é o melhor parâmetro para classificar processos atmosféricos e assinala que para a maior parte deles a relação entre parâmetros geofísicos e escala espacial derivada do resultado empírico é desconhecida, o que torna arbritária a compartimentação pela escala horizontal. Mesmo assim, ele considera o uso da escala de tempo mais problemática do que a escala espacial, devido a processos físicos que tornariam a classificação ambígua. ORLANSKI sugere a divisão da escala no sentido probabilístico (procura de um certo intervalo de escala que apresente a máxima probabilidade de conter o fenômeno a ser classificado), propondo o uso de sufixos gregos (macro, meso e micro) em conjunto com letras também gregas para subdividir os níveis escalares. Em sua proposta final, apresenta esquema tridimensional, tendo por coordenadas escala espacial em $\mathrm{km}$, escala temporal em horas e escala espacial vertical em metros. São expostos cinco planos criados por essa estrutura, que abarcariam os diferentes fenômenos atmosféricos.

Ao discorrer sobre esse tema, LINACRE (1981) argumenta que cada clima compreende um espaço tridimensional, em que um nível maior estaria situado acima dos climas de menor extensividade, com ação recíproca entre as camadas, associando-se a um intervalo de tempo e velocidades características a essas escalas. Especifica seis níveis escalares hierarquizados, suas influências meteorológicas dominantes, extensão horizontal máxima, altitude da camada de uniformidade horizontal, processos relevan- tes, prazo e velocidades específicas do movimento. São eles: 1 . clima planetário: $40.000 \mathrm{~km}$ de extensão horizontal máxima, com altitude da camada de uniformidade horizontal de $15 \mathrm{~km}$, com prazo característico de um ano; 2. clima sinótico: $4.000 \mathrm{Km}$ de extensão horizontal máxima, com altitude da camada de uniformidade de 2 a $15 \mathrm{~km}$ e prazo característico de uma semana; 3. mesoclima: abrangendo área regional $(200 \mathrm{~km})$, com altitude da camada horizontal de 0,5 a $2 \mathrm{~km}$ e duração típica de $8 \mathrm{~h}$; 4 . topoclima: estendendo-se por $10 \mathrm{~km}$ de altitude de $0,01 \mathrm{a}$ 0,5km, com prazo característico de 20 minutos; 5. microclima: extensão de $0,1 \mathrm{~km}$ com altitude da camada de uniformidade horizontal entre 0,0001 e $0,01 \mathrm{Km}$ e prazo de 20 minutos e 6 . clima superficial: com extensão da ordem de $0,0001 \mathrm{~km}$, altitude até $0,0001 \mathrm{Km}$, com prazo característico de um segundo.

\section{CONSIDERAÇÕES FINAIS}

A posição dos autores demonstra haver grande controvérsia quanto à terminologia aplicada às taxonomias do clima, o que compromete o entendimento dessa questão teórica básica. Ressalta-se que os fenômenos atmosféricos constituem-se em objeto de estudo primário de geógrafos e meteorologistas, que avaliam as transformações nesse meio com propósitos diferentes, interessando também a diversas outras áreas do conhecimento que lidam com a interação da atmosfera com a biosfera, geosfera e oceano. Há também diferenças marcantes no tocante à abrangência territorial de cada unidade de escala, tempo de duração e à própria definição de quais processos estariam envolvidos em uma certa unidade escalar, bem como fatores intervenientes e graus de importância a serem atribuídos aos níveis espacial e temporal, entre outros aspectos. Entretanto, os autores demonstram preocupações comuns, como interferências entre níveis escalares, pressupostos básicos similares como condicionates que promovem modificações dos níveis mais amplos para inferiores - e concordância com referência à tridimensionalidade das combinações atmosféricas.

Considerando que os fenômenos climáticos interferem diretamente em vários aspectos do meio fisico, biótico e nas atividades econômicas e sociais, a definição precisa e una das escalas do clima é um fato que interessa não apenas às ciências atmosféricas, mas a todas as ciências ambientais que se utilizam desses conhecimentos. 


\section{REFERÊNCIAS BIBLIOGRÁFICAS}

LINACRE, E. 1981. Características das várias escalas do clima. Boletim da Sociedade Brasileira de Meteorologia, (5), p. 11-14.

ORLANSKI, I. 1975. A rational subdivision of scales for atmospheric processes. Bulletin of the Americam Meteorological Society, 56(5), p. 527-530.

RIBEIRO, A.G. 1992. As escalas do clima. Rio

Claro, Boletim de Geografia Teorética, (23), p. 288-294.

\section{Endereço da autora:}

Lucí Hidalgo Nunes - Instituto Geológico - SMA - Av. Miguel Stéfano, 3.900 - 04301-903, São Paulo, S.P.Brasil.E-mail: lhidalgo@usp.br 